\title{
A time series model to predict the runoff ratio of catchments of the Kalu ganga basin
}

\author{
M.A.P De Silva \\ Department of Mathematics and Computer Science, The Open University of Sri Lanka, Nawala, Nugegoda.
}

Revised: 04 January 2006; Accepted: 02 March 2006

\begin{abstract}
Forecasting runoff ratio variation is important since it can be used to calculate the runoff of a river catchment for a given rainfall on a particular day. The model SARIMA (Seasonal Auto-Regressive Integrated Moving Average) developed for this purpose which was based on Auto Correlation Function (ACF) and Partial Auto Correction Function (PACF), was fitted to the runoff ratio data of the Ratnpura catchnent of the Kalu ganga basin. The appropriateness of the same model was tested against two other catchments; Dela and Ellagawa of the same river basin and found to be suitable.
\end{abstract}

Key words: ACF (Auto Correlation Function), catchment, PACF (Partial Auto Correlation Function), ranfall, river basin, runoff ratio

\section{INTRODUCTION}

Water is one of the most important natural resources of the world. Proper management of this scare resource is everyone's responsibility, because availability of water for human usage is decreasing rapidly. In this context, management of rainwater also plays an important role. Rainwater runoff is another vital aspect in hydrological analysis. Therefore studies of the rainfall, runoff and runoff ratio are of immense value to understand hydrological complexity.

In this study, the short-term variation of runoff ratio has been investigated. A model was derived to forecast the runoff ratio of the Rathnapura catchment of the Kalu ganga basin. SARIMA (Seasonal Auto-Regressive Integrated Moving Average) model was fitted to the runoff ratio. The data of Dela and Ellagawa catchments of the same river basin were used to verify the derived model.

\section{METHODS AND MATERIALS}

Rainfall data were obtained from the Department of Meteorology and discharge data were collected from the Hydrology Division of the Department of Irrigation. One hundred and ninety five monthly discharge data and rainfall data (from October 1978 to December 1994) were used in the analysis. Thiessen's Polygon method' was used to calculate the total average monthly rainfall of the relevant catchment using rainfall data measured in stations around the catchment.

The runoff component was calculated by subtracting the base flow from discharge data for each month. Runoff was divided by (monthly) the average rainfall to obtain the runoff ratio. A time series plot of the runoff ratio was used to identify the trend and seasonal variation. The trend and seasonal variation were removed using differencing methods to make the series stationary.

Identification of the model was based on the graphs of Auto Correlation Function (ACF) and Partial Corrlation Function (PACF). ${ }^{2}$ The model was fitted using Minitab (Version 14) software. Validity of the assumptions of the model was confirmed by analyzing residuals.

Applicability of the model derived for the Ratnapura catchment was tested for the two catchments of Dela and Ellagawa.

\section{RESULTS}

The time series plot of calculated runoff ratio for the Ratnapura catchment is shown (Figure 1). According to the figure, a mild upward trend and a seasonal variation can be seen. The trend and seasonal variation were removed by using the method of differencing to make the series stationary. First difference was used to remove the trend and difference at lag 12 was used to 


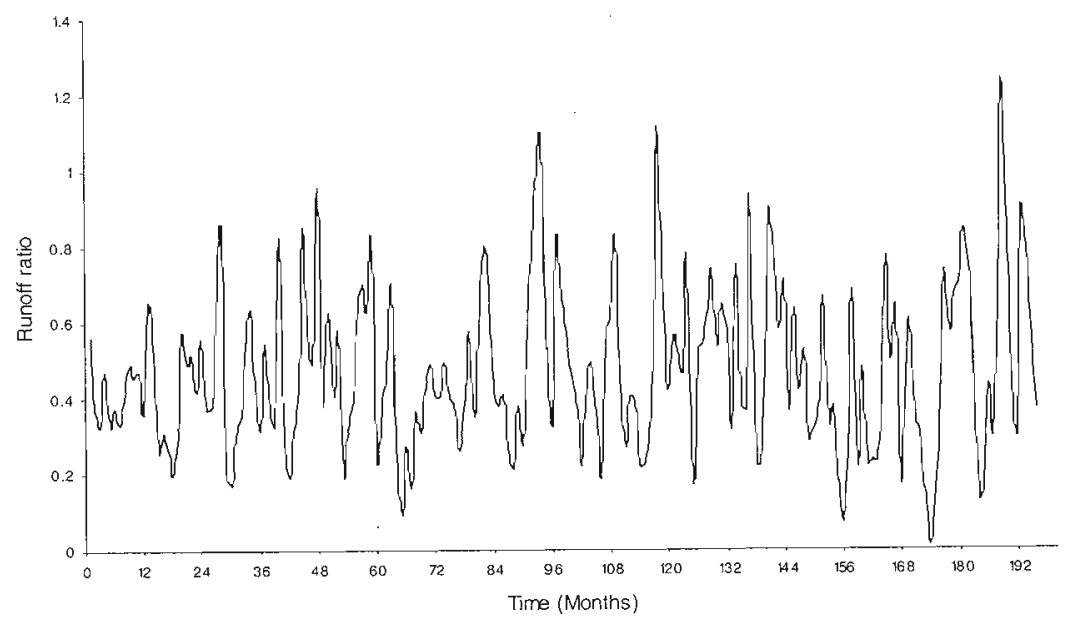

Figure 1: Runoff ratio of the Ratnapura catchment

remove the seasonal variation. Graphs of ACF and PACF of the de-trended and de-seasonalized series are shown in Figure 2 and Figure 3 respectively.

Parameters p, d, q, P, D \& Q of SARIMA (p, d, q, P, $\mathrm{D}, \mathrm{Q})$ model, $\phi_{\mathrm{p}}(\mathrm{B}) \Phi_{\mathrm{p}}\left(\mathrm{B}^{\mathrm{s}}\right) \nabla^{\mathrm{d}} \nabla_{s}^{D_{\mathrm{t}}}=\theta_{\mathrm{q}}(\mathrm{B}) \Theta_{\mathrm{Q}}\left(\mathrm{B}^{\mathrm{s}}\right) \mathrm{Z}_{\mathrm{i}}$ were identified using the graphs of $A C F$ and $P A C F$. It was found that $\mathrm{p}=\mathrm{O}, \mathrm{d}=1, \mathrm{q}=1, \mathrm{P}=0, \mathrm{D}=1$ and $\mathrm{Q}=1$.
Therefore the selected model is SARIMA (011)(011)12. The estimators of parameters are highly significant $(p<0.005)$. Values of Modified Box-Pierce Chi-square statistic show that the fitted model is adequate for the runoff ratio data. ${ }^{3}$

Therefore the model fitted was

$X_{t}-X_{t-1}-X_{t-12}+X_{t-13}=Z_{t}+0.9068 Z_{t-12}+0.8631 Z_{t-1}+0.7827 Z_{t-13}$

Auto- correlation Function for Ratio

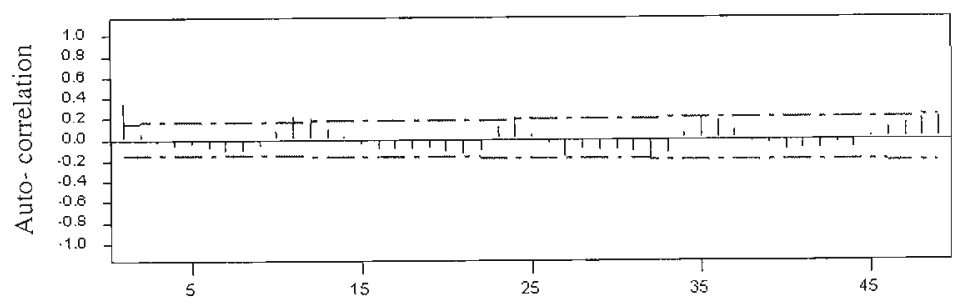

Figure 2: Auto-correlation function for de-trended $\&$ de-seasonalized data

Partial Auto- correlation Function for Ratio

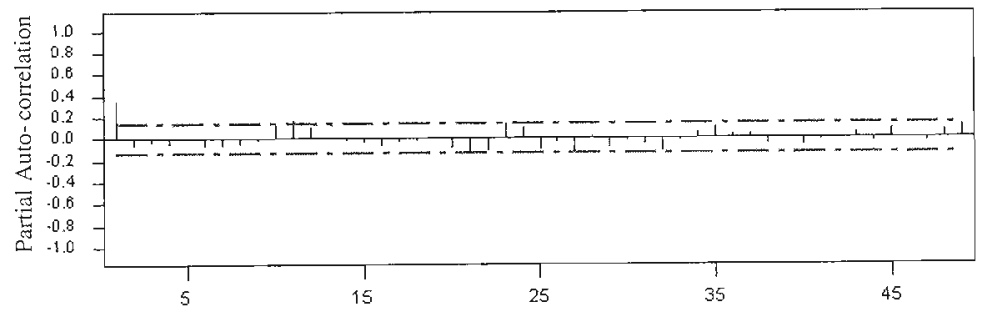

Figure 3: Partial auto-correlation function for de-trended $\&$ de-seasonalized data 
where $X$, is runoff ratio at time $t$ and $Z$, is a purely random process.

All model assumptions were validated by the residual analysis. It ensures that the derived model is appropriate to forecast the runoff ratio data of the Ratnapura catchment.

The same SARIMA (011)(011)12 model was fitted to the data of the Dela and the Ellagawa catchments. It was found that the estimates of parameters of the fitted models were highly significant for the data of above two catchments. Therefore the runoff ratio values of Dela and Ellagawa catchments also satisfied the model SARIMA (011)(011)12. Hence the model derived for Ratnapura catchment could be used to forecast the runoff ratio of the catchments of Dela and Ellagawa as well.

\section{DISCUSSION}

It was found that there is a mild positive trend (per year) in the runoff ratio values of the Ratnapura catchment ( 0.0074 per year). The gradient of the trend line of the runoff ratio data of the Dela catchment was (0.017 per year) more than that of the Ratnapura catchment. This increase in gradient is possibly due to gem mining in the catchment area. According to the information obtained from the villagers, the people of the Dela area have also started mining in the recent past (around 1978). This can be the reason for the upward trend in the runoff ratio of the Dela catchment.

In comparison to Ratnapura and Dela, the gradient of the trend line of runoff ratio for Ellagawa was quite small $(=0.0002$ per month). Almost all changes (affecting the runoff ratio) of the area had been completed before the beginning of the study period. The very small trend of the runoff ratio may be due to the above.

In conclusion, it can be stated that the SARIMA(011)(011)12 model is appropriate to model the runoff ratio of the catchments of Ratnapura, Dela and Ellagawa in the Kalu ganga basin. However, further investigation is necessary to conclude whether this model is appropriate to forecast the runoff ratio of other catchments in Sri Lanka.

\section{Acknowledgment}

The author is grateful to the Hydrology Division of Irrigation Department and the Meteorology Department for providing the required data for the study. The co-operation given by $\mathrm{Mr}$. P Dias of the Department of Statistics and Computer Science of the University of Sri Jayawardhanapura is also acknowledged.

\section{References}

1. Wilson E. M. (1969). Meteorological data. In: Engineering Fydrology. pp. 24-25. Macmillan Publishers Lid. Houndmills, Basing stoke Hampshire, RG212xs, London.

2. Chatfield C. (1975). Estimation in the time domain. In: The Analysis of Time Series; An Introduction. pp. 49-61. Chapman \& Hall, 2-6 Boundary Row, London SE18HN, UK.

3. Gaynor Patricia E. \& Kirkpatrick Rickey C. (1994). Box-Jenkins Methodology- Nonseasonal Models. In: Introduction to TimeSeries Modeling and Forecasting in Business and Economics. pp. 428-430. McGraw-Hill Book Co., San Juan, Singapore. 